\title{
O Processo de Desospitalização de Pacientes Asilares de uma Instituição Psiquiátrica da Cidade de Curitiba
}

The uninstitutionalization process of pacients in a Psychiatric institution in

Curitiba city

Resumo - O alto índice de pacientes asilares nas instituições psiquiátricas representa um dos maiores desafios ao processo da reforma psiquiátrica em curso no Brasil. O intuito desta pesquisa foi o de acompanhar e descrever o processo de desospitalização de pacientes crônicos e asilares que vem ocorrendo em uma dessas instituições. Verificou-se que, nos raros casos em que o paciente asilar é desospitalizado, ele não é desinstitucionalizado e sua situação de tutela é mantida. O processo exige uma política de inclusão que implique não apenas mudanças na estrutura de serviços mas também uma nova clínica apoiada na ética do sujeito.

Palavras-Chave: Reforma psiquiátrica, paciente asilar, desospitalização, desinstitucionalização.

Abstract - The high patient rate in mental hospitals represents one of the highest challenges to the ongoing psychiatry reform process in Brazil. This research's main target was to accompany and describe the process of releasing the chronicle inmates and patients who live in hospital that has been happening in one of these institutions. It turns out that in the rare cases when an inmate is released from the institution, he's not uninstitutionalized and his custody remains. The whole process demands an inclusion policy that implies not only the structure changes but also a new institution based on the subject's ethic.

Key Words: Psychiatry reform, patients who live in a hospital, process of hospital release, uninstitutionalized.

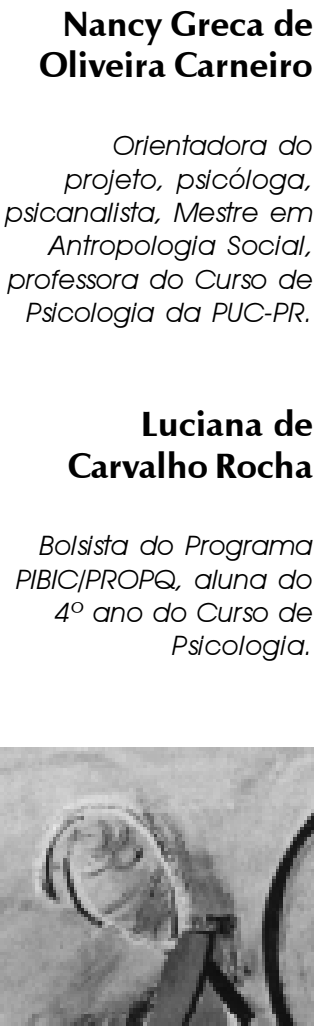

66

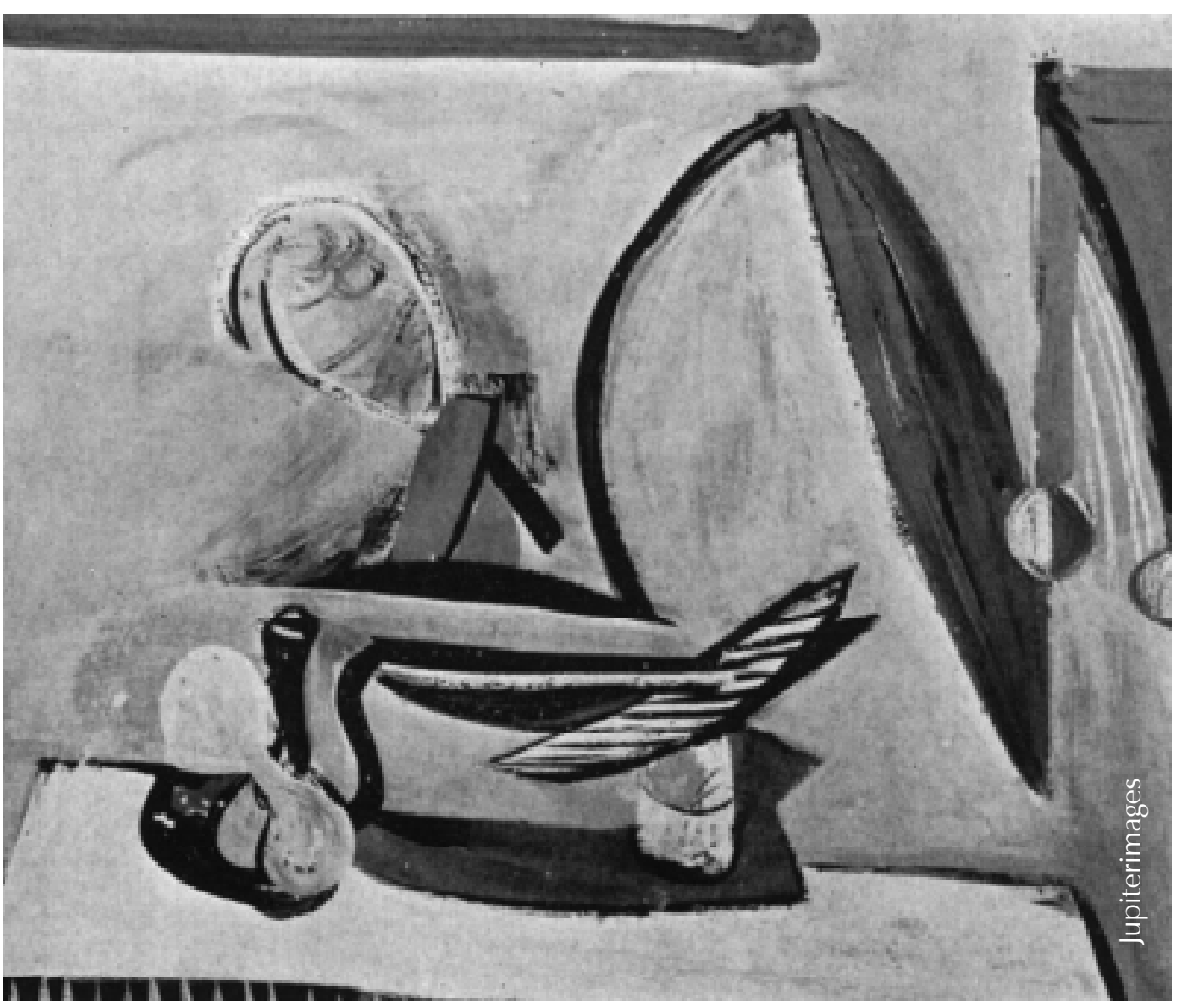




\section{Um Breve Relato da História Institucional da Loucura}

Com a desarticulação dos grandes hospitaisdepósitos do século XVIII, que abrigavam mendigos, prostitutas, criminosos etc., surgiram os manicômios, que, fiéis ao espírito humanista e racionalista de Pinel $^{1}$, organizaram-se no sentido de proteger, amparar e reeducar o doente mental. Esse modelo manicomial fortemente centralizado na figura do alienista, que acumulava os poderes de administração (ambiente protetor e fortemente normatizado), jurídicos (internamento compulsório) e terapêuticos (tratamento moral), vai dando lugar a procedimentos cada vez mais violentos, repressivos e estigmatizantes. Surgem os manicômios-asilos, onde o doente entra para "não mais voltar" (Pessotti, 1996).

Quando, em meados do século XX, as concepções organicistas se impuseram sobre o tratamento moral de forma mais definitiva, o doente mental emergiu em seu status completo de alienado e medicalizado (Castel, 1978).

Nesse contexto, surgem os hospitais psiquiátricos clássicos, em que a instituição se organiza em uma série de disposições graduadas em torno das enfermarias, unidades administrativas denominadas "serviços", e da possibilidade de o paciente vir a ter "alta". As enfermarias se estruturam em níveis graduados: Ala C, dos "loucos varridos"; Ala B, dos "loucos inofensivos"; e Ala A, daqueles passíveis de receberem "alta hospitalar". Nessas instituições, já é possível encontrar vários serviços chamados de "paramédicos", como os de enfermagem e de assistência social. $\bigcirc$ tratamento é assentado quase que exclusivamente em técnicas coercitivo-punitivas e na administração de psicofármacos. Essas instituições, descritas como "instituições totais" por Goffman, podem ser exemplificadas pelos conventos e prisões, e caracterizam-se por interromper, ou mesmo eliminar, o contato de seus moradores com a comunidade e restringir esses contatos ao interior da vida institucional (Goffman, 1990).

Nas décadas de 70/80, o movimento antipsiquiátrico que se desencadeia em torno de Laing e Cooper apresenta uma contundente crítica à psiquiatria institucional que questiona seus próprios métodos e reivindica para a loucura um novo status existencial (Laing, Robert e Cooper, David, 1969). A idéia de comunidade terapêutica em que "todos curam" dá lugar à ação da equipe multidisciplinar, rompendo com a exclusividade do modelo médico-psiquiátrico e incorporando profissionais de diversas áreas (psicólogos, terapeutas ocupacionais, sociólogos etc.). Inaugura- se, assim, o conceito de "trabalhador em saúde mental" (Baságlia, 1978). Essas instituições tendem ao uso de técnicas de natureza persuasivomanipulatórias (sofisticados sistemas de punição e recompensa) ao invés do uso de técnicas de natureza coercitivo-punitivas, base do tratamento moral do século XIX. No quadro da política de

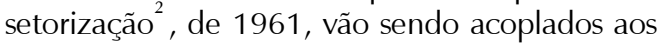
sistemas de internamento outros serviços, como os de hospitais-dia, hospitais-noite ou pensões protegidas e oficinas terapêuticas.

No Brasil, a necessidade e urgência de melhora e democratização dos serviços prestados na área de saúde mental tem sido apontada por técnicos e usuários, de forma sistemática, desde a década de 80, quando o Movimento dos Trabalhadores em Saúde Mental (1987) assume-se enquanto movimento social e não como uma reivindicação de técnicos (Amarante,1994). Com o Projeto de Lei n.o 8, de $1991^{3}$, que dispõe "sobre a extinção progressiva dos manicômios e sua substituição por outros recursos assistenciais e regulamenta a internação psiquiátrica compulsória", deu-se continuidade a um processo de reforma psiquiátrica que se pretende assentar em uma clínica antimanicomial que "opere no sentido contrário ao da exclusão" (Lobosque, 1997).

As doenças mentais, vulgarmente identificadas pelo senso comum com a loucura, acabam por abranger um número diverso de manifestações ideativas, de comportamento e de conduta que vão desde as deficiências mentais, excentricidades e bizarrices, até as conhecidas "entidades mórbidas", descritas pela psicopatologia ocidental. Sabe-se que a loucura, enquanto fenômeno biopsicossocial, está intimamente ligada à história de suas instituições, marcadas por um longo percurso de exclusão e segregação social. Essa estrutura institucional tem mostrado ser insuficiente e inadequada para o atendimento de pacientes em condições de sofrimento mental e vem sendo substituída por serviços alternativos mais humanos, menos estigmatizantes, menos violentos, baseados em um novo modelo que impede o favorecimento de processos de exclusão social.

Assistiu-se, nas últimas décadas, num longo processo de desinstitucionalização da loucura, à emergência de serviços assistenciais alternativos que vão desde o serviço ambulatorial, que evita o internamento compulsório e acompanha o paciente egresso após a alta, até o sistema de pensão protegida, no qual o paciente mantém vínculo ocupacional e profissional fora da instituição, o sistema de hospital-dia, no qual o paciente é mantido no convívio familiar e permanece na instituição durante o dia para atividades terapêuticas, ocupacionais ou recreativas,
1 Com Pinel (1745-1826), expressão máxima do humanismo iluminista, do espírito libertário fiancês $e$ do racionalismo científico, reconhecem-se as origens de uma verdadeira psicopatologia e, em torno de suas idéias, define-se $o$ aparato institucional que, através dos séculos, ocupar-se-á da loucura.

2 A lógica que cria a lei de 1838 acerca dos alienados é a mesma e idêntica à que se exprime na circular de março de 1960 sobre a setorização do atendimento psiquiátrico, que cria novas concepçóes para os hospitais psiquiátricos na França.

3 Em 1989, o então deputado Paulo Delgado apresenta o Projeto de Lei no3657, que contempla os principais pontos da reforma psiquiátrica. Esse Projeto de Lei foi aprovado no ano de 1999 e, finalmente, a Lei foi sancionada pelo Presidente Fernando Henrique Cardoso em abril de 2001. Dispóe sobre a proteção e os direitos das pessoas portadoras de transtornos psíquicos e redireciona o modelo assistencial em saúde mental através da extinção progressiva dos manicômios e sua substituição por outros recursos assistenciais. 
e as residências terapêuticas, que são casas localizadas na comunidade, supervisionadas por uma equipe de profissionais que têm o intuito de promover a desospitalização de pacientes asilares sem vínculos familiares e sociais. Acrescente-se, a essas, outras iniciativas institucionais, como os NAPS e/ou CAPS (núcleos de assistência psicossocial e/ou centros de assistência psicossocial), ou comunitárias, como as associações de psicóticos, amigos e familiares.

Tabela 1 - Serviços assistenciais alternativos.

\begin{tabular}{|l|l|l|l|} 
NAPS e/ou CAPS & Hospital-dia & Pgressos & Pensão protegida \\
& & Ambulatório & $\begin{array}{l}\text { Associação de } \\
\text { psicóticos, amigos e } \\
\text { familiares }\end{array}$ \\
\hline
\end{tabular}

Esses serviços permanecem, em geral, acoplados às antigas instituições de internamento, hospitais psiquiátricos ou clínicas particulares, o que ainda mantém o sujeito com uma doença mental em condições de tutela institucional. As iniciativas comunitárias e mesmo as de organizações criadas e conduzidas por esses serviços são raras. Observase, nos últimos anos, no entanto, a formação de grupos de auto-ajuda no Brasil, criados e conduzidos por portadores de transtornos mentais que, inspirados no movimento originário dos alcoólicos anônimos, assinalam a emergência de profundas mudanças sociais.

\section{O Campo Institucional}

Com o intuito de realizar um reconhecimento dos serviços prestados à área de saúde mental na cidade de Curitiba, alunos da disciplina de Psicopatologia do Curso de Psicologia da Pontifícia Universidade Católica do Paraná visitaram vinte e uma instituições particulares e públicas entre os anos de 1997 e $2000^{4}$. Com essas visitas, constatou-se a coexistência de todos os modelos acima mencionados, em um evidente processo de modernização desses atendimentos, inclusive nas que ainda mantêm uma estrutura mais clássica. $\mathrm{O}$ modelo exclusivamente asilar encontra-se praticamente extinto, e, embora algumas instituições se assentem no internamento, nelas se organizam movimentos de constituição de equipes multidisciplinares e a implantação de novas estratégias de atendimento, que visam a manter o paciente em seu meio e evitam os processos de segregação e exclusão.

4 Esse trabalho acadêmico, previsto no programa curricular da disciplina de Psicopatologia, foi supervisionado pelas professoras Nancy Greca de Oliveira Carneiro e Célia Montenegro, professoras do Curso de Psicologia da PUC-PR.
A estrutura da instituição onde se realizou a presente pesquisa, concebida no início do século nos moldes dos manicômios-asilos, caracterizouse por uma política de saúde mental que se definia em torno de poucos elementos: uma concepção classificatória apoiada em nosologias clássicas, uma tecnologia de intervenção restrita ao tratamento moral e, posteriormente, a medicalização, uma organização institucional constituída por 68 psiquiatras e pessoal auxiliar, e o usuário, que, na lei de 1838, é definido como tutelado pelo Estado.
Esse dispositivo, apesar de viver profundas tensões internas, conflitos e mesmo mudanças no sentido de sua modernização, manteve quase que intactos seus elementos constitutivos. A instituição vem, hoje, vivendo uma nova fase. Propostas de modernização, que incluem esforços no sentido da humanização da assistência à saúde mental, o reconhecimento dos direitos à cidadania das pessoas acometidas de transtornos mentais, a implantação de novos serviços, além de programas de desospitalização de pacientes crônicos e asilares, começaram a ser discutidos e elaborados.

As mudanças no sistema de atendimento à saúde mental são complexas e envolvem desde a busca da singularidade do sujeito em estado de sofrimento psíquico à recuperação das funções terapêuticas do hospital psiquiátrico e à ampliação de serviços oferecidos, inclusive a regionalização e extensão dessa rede de assistência para dentro das comunidades. A necessidade de que essas mudanças, hoje vividas pelos hospitais psiquiátricos, sejam planejadas, estruturadas e acompanhadas justifica a realização desse projeto por encontrar, no alto índice de pacientes asilares, moradores da instituição, um dos seus maiores desafios: quem são e para onde irão esses pacientes?

A intenção desta pesquisa foi, portanto, a de acompanhar e descrever o processo de desospitalização de pacientes crônicos e asilares que vem sendo realizado na instituição, desde o momento de definição do paciente a ser desligado do internamento (diagnóstico de sua situação geralpsiquiátrica, psicológica e social), seu desligamento (determinação de seu destino e de seu futuro vínculo com a instituição), o reconhecimento geral de seu ambiente de acolhimento (quem o acolherá e em que condições) e, finalmente, as dificuldades que encontrará no processo de adaptação ao seu novo ambiente.

\section{Metodologia}

O hospital possui $1700 \mathrm{~m}^{2}$, contando com 9 (nove) unidades de internamento, 1 (um) hospital-dia e 
serviço de ambulatório. Participaram da pesquisa apenas duas das unidades selecionadas pelo serviço social da instituição.

O caráter essencialmente qualitativo dos dados possibilitou trabalhar com poucos informantes, a saber: o corpo técnico do hospital, o paciente asilar e um representante de sua família. Na tentativa de caracterizar o perfil do paciente asilar nessa instituição, foram realizadas entrevistas semiabertas com o corpo técnico das unidades que participaram da pesquisa, e a análise do material conduziu-se a partir da análise das representações ${ }^{5}$ que esses possuem a respeito do paciente asilar. Na próxima etapa, a partir de questionários semiabertos, pretendeu-se identificar as condições sociofamiliares encontradas por ocasião da desospitalização do paciente e discriminar as principais dificuldades de adaptação enfrentadas pelo egresso ${ }^{6}$ e seus familiares em seu processo de reinserção social.

Dessa forma, os dados quantitativos foram obtidos em pesquisa documental e os dados qualitativos foram obtidos através de observações participantes e de entrevistas semi-abertas com os profissionais que compõem a equipe técnica das unidades, com o paciente e com o familiar responsável.

Os dados quantitativos foram tabelados e os dados qualitativos foram interpretados a partir da concepção de representação social e através da literatura disponível acerca da reforma psiquiátrica, em curso no Brasil.

\section{Resultados}

A instituição, fundada no começo do século passado, mantém, ainda hoje, características marcantes de um sistema asilar manicomial e passa, atualmente, por um processo de significativas transformações. Está profundamente comprometida com a necessidade de reencaminhar pacientes que estão há vários anos internados ao convívio familiar e social. No entanto, no decorrer dos contatos com a instituição, verificou-se a absoluta ausência de um programa oficial estruturado de desospitalização de pacientes asilados. Observou-se, ainda, que, ao longo de sua história, as altas de pacientes asilados vêm acontecendo de maneira lenta e esporádica, intensificando-se apenas a partir do começo do ano de 2001, em resposta a uma demanda da atual administração, em consonância com as atuais políticas de saúde em processo de implantação no País.

Entrevistaram-se oito profissionais, dos quatorze que atuam nas duas unidades selecionadas, entre eles, dois médicos psiquiatras, dois psicólogos, dois enfermeiros e duas assistentes sociais da Unidade 1 e da Unidade 2, conforme está apresentado na figura que se segue.

Figura 1 Porcentagem de profissionais da equipe técnica que foram entrevistados.

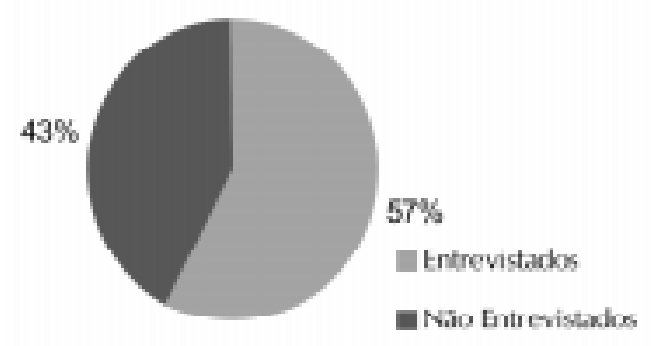

Quando questionados sobre a existência de um programa de desospitalização de pacientes asilados, apresentaram diferentes respostas:

... "estamos desenvolvendo isso aí, de desospitalização, dando alta para os pacientes que as famílias tem possibilidade de atender e encaminhando também para pensões protegidas, casas de repouso, caso as famílias tenham condições de sustentar seus familiares nestes lugares" (médico psiquiatra).

..."Que eu saiba até este momento, existe sim todo um estudo, todo um levantamento de dados sobre quais são os pacientes, quantos são, há quanto tempo estão aqui e uma tentativa, principalmente um movimento da direção, de promover esta desospitalização. Só que eu estou te dizendo isso de ouvir falar, não foi assim "olha, você vai a partir do ano que vem fazer isso e isso, psicólogo tal, assistente social tal ", eu sei que existe, mas não está assim "isso é uma ordem já" (psicóloga).

..."não que eu esteja sabendo assim diretamente ... eu não sei se já foi feito, mas eu acredito que não" (assistente social).

... "o programa que eu sei não é bem um programa, são atitudes que o pessoal está tomando quanto a essa questão" (enfermeira).

Pode-se observar que não há um consenso ou idéia geral, entre a equipe, acerca dos procedimentos necessários e sistemáticos para a desospitalização desses pacientes e, embora os técnicos estejam sensibilizados nesse sentido, cada profissional possui suas próprias idéias acerca do trabalho realizado junto aos pacientes.

Esse fato pôde ser observado também na aparente autonomia e independência que cada unidade possui entre si e em relação à totalidade da
5 O conceito de representação é empregado originalmente por Durkheim (1970) como base sobre a qual se constrói a vida social. As representações originam-se das relações que se estabelecem entre individuos assim combinados ou entre grupos secundários que se intervalam entre o indivíduo e a sociedade total. 
instituição. Dessa forma, não há um programa ou filosofia do hospital no que diz respeito à forma e aos procedimentos necessários e comuns a todas as unidades no sentido da desospitalização.

Na instituição, em 07 de fevereiro de 2002, o número de internados era de 496 pacientes; destes, 144 eram pacientes asilares. Estipulou-se, como parâmetro para este trabalho, que o paciente asilar é o que está internado no mínimo há cincos anos na instituição. Assim, a instituição possui, ainda, $29 \%$ de pacientes asilares, conforme está apresentado na figura que se segue. Na listagem fornecida pelo setor de internamento, consta, como internamento mais remoto, o ano 1951.

Figura 2 Porcentagem de pacientes asilares internados na instituição.

\section{Internamentos em 07/02/2002}

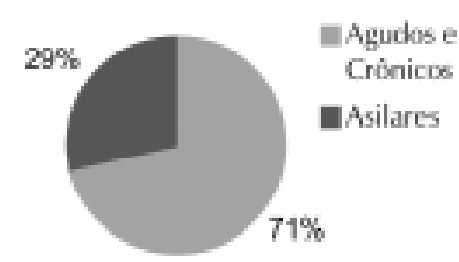

6 Entende-se por "egresso" o paciente que, a partir de uma série prolongada e sistemática, com vários internamentos intermitentes em sua história pessoal, encontra-se em um processo de alta e de retorno ao convívio social.

7 Em seu livro, no capítulo "A carreira moral do doente mental", cujo eixo principal é a seqüência regular de mudanças que a carreira provoca no eu da pessoa e em seu esquema parajulgar a si mesmo e aos outros, o autor realiza uma análise da caminhada progressiva e conseqüente desubjetivação do "eu" de uma pessoa que passa por um processo de apropriação $e$ objetivação pela instituição assumindo, assim, a identidade de "doente mental". Essa carreira possui três principais fases, que são a de pré-paciente, a fase de internamento e a fase do exdoente.

Um paciente internado há tantos anos em uma instituição psiquiátrica passa por um longo processo de desconstrução da personalidade. Despojado de suas referências pessoais, hábitos e relações sociais, despojado de defesas e mecanismos de adaptação usuais, o sujeito entra no anonimato promovido pelas estruturas institucionais. Ocorre uma despersonalização, ao final da qual o sujeito se identifica com a categoria de doente mental. Esse processo é abordado por Goffman (1990) ${ }^{7}$, que tanto contribuiu para esclarecer os mecanismos pelos quais as "instituições totais" (hospícios, prisões, conventos etc.) agem nos sentimentos de identidade e na construção da pessoa estigmatizada, com ou sem o seu consentimento.

Outra constatação importante é que o sistema de documentação para a localização do paciente é precário; o registro dos pacientes só foi adotado em 1933, fichas individuais, a partir de 1940, e os prontuários de evolução clínica, a partir de 1960.

A localização dos pacientes asilares recém desinstitucionalizados foi dificultada,e, a partir dos voltaram ao convívio familiar. Dentro da outra parcela da amostra, seis pacientes foram para casaslares ou casas de repouso após a desospitalização; três foram novamente internados e quatro pacientes não foram localizados devido à mudança do número do telefone e da precariedade das informações sobre sua localização nos prontuários. Esses dados são apresentados, por porcentagem, na figura que se segue.

Figura 3- Destino dos pacientes asilares após sua desospitalização.

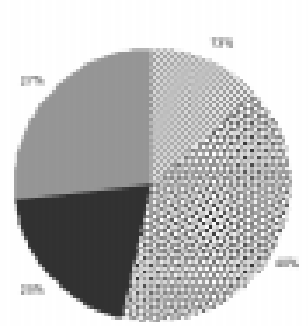

\& Esta em Casa

Y. Estajo em Casas de Repous: e Casas Lares

Foram Nowamense Incernados

Nản Foram Localizados raros contatos telefônicos com o familiar do paciente em que se obteve êxito, pôde-se observar que, após a desospitalização, dentro da amostra pesquisada, de quinze pacientes, apenas dois

Dessa forma, foi possível realizar contato com pacientes que foram desospitalizados e voltaram ao convívio familiar apenas em dois casos. No caso do primeiro paciente, por ocasião da visita, ele estava agitado e agressivo, e a pessoa responsável por ele não pôde atender a pesquisadora. Com o segundo paciente, realizou-se a entrevista programada, mas, devido ao quadro de deficiência mental, não se conseguiu obter.

Conclui-se que o paciente asilar da instituição não vem sendo encaminhado à família e que os laços da instituição com o grupo familiar, do internamento à alta, não se estabelecem de forma sistemática. O processo de desospitalização alcança apenas uma das alternativas possíveis: o encaminhamento a outras instituições (asilo, casas de repouso, casas-lares). Dessa forma, embora haja desospitalização, não há desinstitucionalização. A partir da análise qualitativa das entrevistas realizadas e demais dados coletados no desenvolvimento da pesquisa, constatou-se ainda que:

Não há um processo sistemático de detecção e seleção dos pacientes asilares que serão desospitalizados, fato esse justificado pelos informantes a partir da alegação que as condições de desospitalização e as dificuldades intervenientes "são muito particulares a cada paciente". Assim, os critérios são circunstanciais e estabelecidos em 
função de casos particulares. Em geral, os critérios utilizados para a determinação da alta dos pacientes asilares são, principalmente: o quadro psiquiátrico geral do paciente e as possibilidades de a família recebê-lo e/ou a existência de alguma outra instituição que possa aceitá-lo. Com isso, o processo ora em curso vem exigindo apenas a participação da Psiquiatria e do serviço social. A alta é vista como responsabilidade exclusiva do médico psiquiatra e o encaminhamento desses pacientes ao convívio social é realizado pelas assistentes sociais. Os demais profissionais não estão envolvidos, fazendo apenas colocações ocasionais referentes a sua área no sentido de possibilitar melhor avaliação de cada paciente.

As etapas ou procedimentos adotados no processo consistem num trabalho de conscientização das famílias por meio dos atendimentos familiares e atendimento do próprio paciente durante os grupos operativos, em relação à necessidade de alta. O contato com a família ou com instituições que possam receber o paciente e seu posterior encaminhamento são realizados pelas assistentes sociais. Nos raros casos em que o paciente é desospitalizado, após a alta, este geralmente não mantém vínculo com a instituição, mesmo esta possuindo os serviços do ambulatório e do hospital-dia disponíveis.

Uma das estratégias adotadas para a desospitalização consiste na concessão de licenças, que permitem que o paciente passe o fim de semana em casa e retorne ao hospital. Outra estratégia do serviço social é a de encaminhar esses pacientes para outras instituições, como abrigos e casas-lares. Um exemplo é a instituição de um programa de implantação da primeira residência terapêutica $^{8}$ da cidade de Curitiba, projeto ainda não realizado por ocasião do levantamento destes dados. No que diz respeito ao encaminhamento do paciente à família, o seu posicionamento no sentido de levar ou não o paciente asilar para casa é decisivo no processo de desospitalização. No entanto, muitos pacientes não possuem família, mas apenas um tutor. E ainda, a família geralmente apresenta grande resistência à desospitalização do paciente, muitas vezes por não possuir estrutura familiar fortalecida e também capacidade de se organizar para receber novamente seu parente portador de transtorno mental. Somando-se a isso, muitas famílias que levam o paciente asilar para casa acabam reinternando-o em outros hospitais ou na própria instituição. Existe também uma parcela de pacientes asilares que, pela idade avançada, vão a óbito. Outro fato presente nesse processo é a dificuldade de o próprio paciente sair do hospital. Depois de anos internado, o paciente acaba por fazer da rotina da instituição a sua própria rotina, e o hospital passa ser a sua casa. Isso justifica a dificuldade encontrada na realização desta pesquisa em encontrar pacientes asilares que realmente voltaram ao convívio familiar e social e "reassumiram suas vidas".

\section{Discussão}

Embora as expectativas de estabelecer um contato com as famílias desses pacientes e conhecer as dificuldades encontradas por ocasião de seu retorno ao convívio familiar e em seu processo de reinserção social tenham sido absolutamente frustradas (ver Figura 3), pode-se construir e delimitar alguns conceitos fundamentais que poderão orientar e oferecer subsídios para um processo de desospitalização de pacientes asilares. Esses conceitos são os de desinstitucionalização e desospitalização, que, muitas vezes, têm o mesmo uso, e a própria noção de paciente asilar, que, apesar de ser uma realidade institucional, não possui uma definição oficial no meio psiquiátrico.

\section{Quem São: Pacientes Agudos, Crônicos e Asilares - e o Sujeito?}

A doença mental, identificada pelo senso comum como loucura, é caracterizada a partir de uma nosografia extensa, altamente especializada do ponto de vista classificatório. No entanto, quando se trata de doença mental, pode-se deparar com um conjunto absolutamente diverso, e muitas vezes contraditório, de representações acerca do que seja a loucura. Nesse sentido, podem-se considerar principalmente três grupos de representações: as representações construídas pelo pensamento científico, orientado em torno de um discurso médico oficial; as representações populares, que correspondem às idéias de natureza artística, religiosa e comunitária, entre outras, e, finalmente, as representações subjetivas do próprio doente e de seus familiares acerca de sua doença. Nesta pesquisa, optou-se por recolher as representações que se constituem entre os técnicos, não a partir do discurso científico, mas enquanto um conjunto de idéias que gera uma ação interpretativa e acaba por nortear suas intervenções junto aos pacientes. Um dos primeiros desafios da pesquisa foi, portanto, estabelecer o perfil do paciente asilar presente no sistema de representações produzido pelos técnicos da instituição: quem são os pacientes asilares?

... "Asilar é aquele paciente que às vezes não tem até condições de família, de proteção familiar. Então ele fica no hospital como se fosse um apoio vital para sua sobrevivência, então é este que seria, ele está asilado no hospital, ele não está propriamente em tratamento, ele fica em observação durante muito tempo, pode até ficar sem medicação em

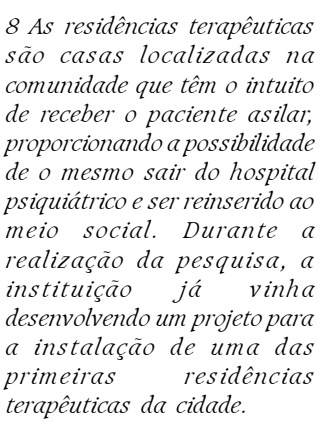




\author{
. "são senhores que \\ têm consciência das \\ coisas, têm \\ consciência que \\ estão abandonados, \\ não lembramo \\ nome da mãe, não \\ lembram o nome do \\ pai, não lembram o \\ sobrenome. Mas \\ estão bem \\ conversam contigo, \\ eles ajudam aqui, \\ ajudam a limpar, vão \\ ajudar na festa de \\ Natal, eles têm uma \\ rotina aqui, eles \\ foram abandonados, \\ têm a doença, claro \\ estão \\ comprometidos, de \\ uma certa forma, \\ mas não são \\ regredidos, não é \\ que eles não estejam \\ em condições de sair
}

lá fora"

assistente social determinados casos, mas freqüentemente ele passa a fazer medicação quando se faz necessário. Mas se não tem família, não tem para onde encaminhar e ele tem um quadro crônico, não é possível dar uma alta para ele pura e simplesmente" (médico psiquiatra).

..."são estes pacientes que têm, de certa forma, vínculo, algum familiar, algum conhecido, mas que foram abandonados aqui" (assistente social).

..."são senhores que têm consciência das coisas, têm consciência que estão abandonados, não lembram o nome da mãe, não lembram o nome do pai, não lembram o sobrenome. Mas estão bem, conversam contigo, eles ajudam aqui, ajudam a limpar, vão ajudar na festa de Natal, eles têm uma rotina aqui, eles foram abandonados, têm a doença, claro estão comprometidos, de uma certa forma, mas não são regredidos, não é que eles não estejam em condições de sair lá fora" (assistente social).

..." é aquele que não tinha, ou não tem, condições de convívio na sociedade, então eles têm que ficar no hospital" (enfermeira).

..."são pacientes que às vezes não têm família, são pacientes que têm família que não os querem levar, que não têm condições muitas vezes" (médico psiquiatra).

..."É o que é morador na instituição, não aquele que está transitoriamente, é aquele que é morador. È uma pessoa difícil de lidar, porque o morador acaba pegando o jeito do local, as manhas, ele sabe que ele não vai embora, ele se acomoda, ele fica meio que dono do espaço" (psicólogo).

..."No momento, os asilados aqui são, ou pessoas com retardo mental severo, a maioria com retardo mental severo, ou esquizofrênicos que já têm grande comprometimento cognitivo" (psicólogo).

..."O asilar, na maior parte, ele não tem problemas psiquiátricos, ele está aqui porque não tem para onde ir, ou ele tem um pequeno distúrbio, uma pequena dificuldade" (médico psiquiatra).

As idéias encontradas entre os profissionais da equipe técnica acerca de quem é o paciente asilar estão intimamente ligadas à noção de cronicidade da doença, o que aponta a necessidade de diferenciar o paciente considerado crônico do paciente considerado agudo. Com isso, faz-se necessária a caracterização do paciente psicótico e a distinção entre a fase crônica e a fase aguda desse transtorno.

... "pacientes aí de 20, 30 internamentos, são crônicos" (médico psiquiatra). ..."pacientes crônicos são aqueles que tiveram vários internamentos e estão sucessivamente sendo reinternados" (médico psiquiatra).

..."O paciente crônico é o paciente comprometido cognitivamente; ele pode ser crônico, mas não asilar" (psicólogo).

..."os agudos não querem ficar no hospital e os crônicos não querem sair..." (médico psiquiatra).

..."paciente agudo é o que tem o primeiro internamento, primeiro, segundo..., e que também não teve internamento a longo prazo" (médico psiquiatra).

Clinicamente, segundo Miranda-Sá Jr. (2001), em Psiquiatria, os limites dos conceitos de enfermidade aguda, subaguda e crônica ainda são imprecisos porque necessitam de fundamentação científica e falta-lhes aceitação universal. Contudo, tais conceitos têm importância clínica suficiente para justificar seu emprego. Não obstante todas as objeções possíveis, pode-se convencionar os seguintes limites: as enfermidades agudas são as que demoram menos de dois meses desde o aparecimento de seus primeiros sintomas até sua completa resolução; as enfermidades subagudas têm duração maior que dois meses e menor que dois anos; as enfermidades crônicas cursam por mais de dois anos.

Portanto, paciente agudo é o que está passando por uma crise, um surto, que, em linguagem psiquiátrica, caracteriza-se por sintomas negativos (perdas ou diminuição em suas funções psíquicas) e por sintomas positivos (discurso desorganizado, presença de delírios e/ou alucinações). O paciente crônico é o que tem uma história de internamentos reincidentes que vêm acontecendo ao longo do tempo ou aquele que se encontra internado há vários anos na instituição, podendo ou não apresentar sintomas psiquiátricos. $\bigcirc$ paciente asilar encontra-se, portanto, identificado com esse terceiro grupo. É importante observar que o critério de cronicidade, nesse terceiro caso, é um critério desprovido de valor clínico e, eminentemente, de valor social. Dessa forma, o conceito de paciente asilar, embora pensado como de natureza clínica na maioria das vezes, é estritamente um conceito de natureza socioinstitucional; pode incluir tanto aquele paciente que se encontra no hospital em um estado crônico da doença, em que os sintomas negativos apontam para uma perda não reversível de algumas de suas funções psíquicas, embora não estejam a manifestar sintomas positivos como a presença de delírios e/ou alucinações, quanto aquele que, mesmo na ausência de sintomas positivos ou negativos, permanece internado na instituição. O paciente asilar é aquele cujo sistema de trocas com a sociedade foi rompido e cuja vida 
relacional restringe-se às relações que ainda mantém no interior da vida institucional. Em outras palavras, o paciente asilar é o morador de uma instituição de modo permanente.

\section{Para Onde Vão: a Desinstitucionalização}

O conceito de desospitalização de pacientes asilados empregado nesta pesquisa está relacionado, principalmente, à noção de desinstitucionalização. Segundo Paulo Amarante (1996), a noção de desinstitucionalização surge nos E.U.A., em decorrência do Plano de Saúde Mental do Governo Kennedy, entendida basicamente como um conjunto de medidas de desospitalização. Alinha seus princípios fundamentais, reproduzidos do Direito do Instituto Nacional de Saúde Mental dos E.U.A.:

a prevenção de internações inadequadas em instituições psiquiátricas, procurando alternativas comunitárias para o seu tratamento;

- retorno para a comunidade de todos os pacientes institucionalizados que tiverem preparo adequado para tal mudança;

o estabelecimento e a manutenção de sistemas de suporte comunitário para as pessoas nãoinstitucionalizadas que estejam recebendo serviços de saúde mental na comunidade.

Pode-se afirmar, ainda, que uma tendência de vários segmentos sociais, inclusive aqueles constituídos de corpo técnico da área, verificável nesse processo de reforma, coloca-se em oposição à desinstitucionalização por entendê-la como mera desospitalização ou, de modo radical, como simples desassistência. Entende-se, nesse sentido, que a desinstitucionalização significaria abandonar os doentes à própria sorte, seja pela premissa crítica, correta, de que seu objetivo pode ser o de reduzir ou erradicar a responsabilidade do Estado para com essas pessoas e familiares, seja por uma compreensão pouco correta das várias implicações biopsicossociais e políticas presentes nesse processo. Ora, a proposta de uma reforma psiquiátrica tenta, principalmente, discutir a reestruturação da atenção à saúde mental, entendendo a palavra "atenção" em seu sentido mais amplo, não somente restrito ao atendimento feito nos hospitais psiquiátricos em regime de internamento. Dessa forma, não pode, em absoluto, representar o "desamparo" dos doentes ou simplesmente o seu envio para fora do hospital, sem ser implantada, antes, uma infra-estrutura na comunidade que permita tratar e cuidar deles e de suas famílias.
Nesse trabalho, concordamos que, nos raros casos em que o paciente é desospitalizado, ele não é desinstitucionalizado, permanecendo sob tutela familiar ou institucional.

\section{Como Estarão: a Família e a Rede Social}

Observa-se, também, em alguns depoimentos, a tendência da equipe em atribuir ao paciente ou a sua família a responsabilidade pelo asilamento, não evocando outras causas, tais como as condições de vida geradas na instituição, a não-vinculação dos familiares ao tratamento ou a ausência de outros serviços comunitários e alternativos ao internamento compulsório. Sobre a família, recai a culpa e a responsabilidade pelo internamento. Cabe ressaltar que os efeitos danosos do internamento, que podem ser em maior ou menor intensidade, estão em relação direta com sua duração, com o número de reincidências e, principalmente, com a rede social que o sujeito mantém com o seu grupo. A situação de crise provocada pela doença mental pode produzir, na unidade familiar, tanto uma completa desintegração quanto a reafirmação desses laços familiares.

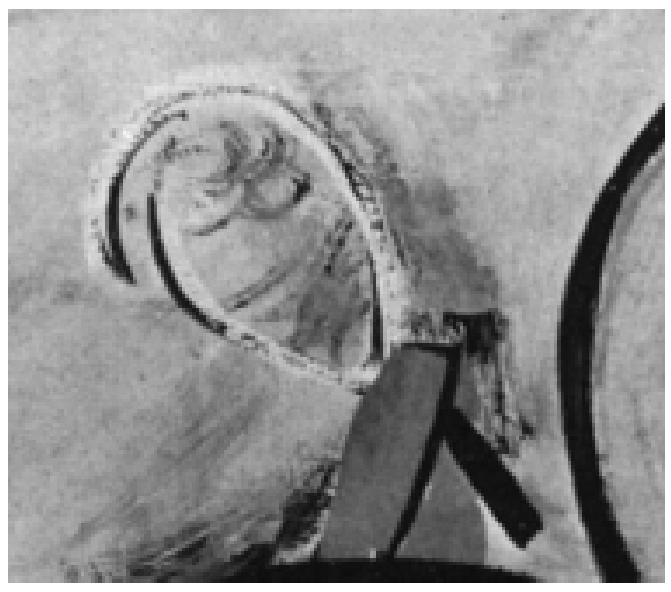

Observa-se, também em alguns depoimentos, a tendência da equipe em atribuir ao paciente ou a sua familia a responsabilidade pelo asilamento, não evocando outras causas, tais como as condições de vida geradas na instituição, a nãovinculação dos familiares ao tratamento ou a ausência de outros serviços comunitários e alternativos ao internamento compulsório.

Famílias que possuem rede social de malha estreita - significando fortes laços sociais com um grupo religioso, parental ou mesmo comunitário - tendem a lidar com situações de crise na sua própria rede de relações (network) ${ }^{9}$, caracterizada por vínculos fortes e próximos. Nesses casos, não só o internamento é evitado ou limitado a curto espaço de tempo, como o processo de reintegração do sujeito é facilitado. Já as famílias que possuem relações de malha frouxa - com poucos e frágeis vínculos com outros grupos - tendem a realizar um movimento contraído em relação ao network, escondem o que está acontecendo e, conseqüentemente, isolam-se. Nesses casos, a
9 De acordo com Bott (1968), do ponto de vista psiquiátrico, essa evolução está determinada pela etiologia e natureza da doença. Do ponto de vista antropológico, está ligada ao conceito de network (rede social) $e$ ao papel da rede social mantida pelo sistema familiar nesses processos. 
estratégia, numa situação de crise, é a de recorrer aos canais formais, aos serviços especializados e ao internamento. $\mathrm{O}$ apelo ao internamento tornase freqüente, a reincidência aumenta. $\mathrm{O}$ risco de desintegração familiar e, em conseqüência, os movimentos de exclusão sobre o paciente e sobre a própria família são menores no primeiro caso que no segundo. Dessa forma, torna-se impensável qualquer processo no sentido da desospitalização que não envolva a família, plano microssocial, e a própria comunidade, plano macrossocial.

\section{Conclusão}

Uma das ações centrais do processo de transformação institucional está em um movimento para evitar a cronificação e o asilamento das pessoas em estado de sofrimento mental. Para isso, podese apontar uma série de providências que deveriam ser adotadas: a redução do período de internamento, a implantação de serviços de ambulatório, de hospital-dia, oficinas terapêuticas e de outros serviços alternativos que não tenham no internamento seu modelo principal de atendimento. $\mathrm{O}$ alto índice de pacientes crônicos e asilares, porém, cuja longa permanência sob tutela do hospital tornou-os "moradores", representa uma grande dificuldade nesse processo. Por gerar uma escassa rotatividade, resulta na limitação das vagas para pacientes agudos e em situação de crise. Exige, além disso, a manutenção de uma série de serviços organizados em torno do internamento, tais como: programas de maternagem aos pacientes mais deficitários, atuação no sentido do resgate da identidade perdida ou deteriorada bem como esforços no sentido de sua desospitalização. O projeto psicoterapêutico da equipe passa a ser pensado em torno dos processos de adaptação do paciente à vida institucional e de esforços no sentido de se evitar a cronificação da doença, em prejuízo do atendimento psicoterápico do paciente e da família.

Nesse sentido, a desospitalização desses pacientes, que tem como objetivo sua reinserção social, encontra, no estado de cronificação da doença, nas condições egóicas e identitárias do paciente e na sua situação social, grandes empecilhos, muitos deles gerados por esse mesmo projeto terapêutico que pretende atendê-lo. Goffman demonstra, em sua análise do que chamou de "instituições totais", o poder das forças institucionais no sentido de imprimir um destino e uma reelaboração social comum da identidade, mesmo em relação à "mais irredutível diversidade" (Goffman, 1988, p.113). Assim, o longo processo de internamento produz uma desconstrução da identidade anterior do paciente, intensas e definitivas rupturas em seus laços familiares e sociais e uma completa identificação com o "doente mental" e com a vida institucional e tutelada.

Embora não contagiosa, a experiência da loucura é envolvente. Afeta e compromete diretamente as pessoas de relações mais próximas e afasta as outras, num sistema de atração e repulsão que, na esfera microssocial, traduz-se num estreitamento e/ou ruptura do network do sujeito e, numa esfera macrossocial, nos fenômenos de exclusão e segregação. Demonstrou-se, ao longo deste trabalho, que o paciente asilar é o produto final de uma ação socioinstitucional e que, embora a loucura tenda a ser pensada como produzindo a ilusão de um simbolismo autônomo, ela atinge a todos, do sujeito à família, da família à comunidade, da comunidade à sociedade.

Dessa forma, não basta desospitalizar. É preciso desinstitucionalizar, pois o que se encontra em jogo não é apenas um novo endereço, seja um asilo, um internato ou mesmo a família, em que a situação de tutela do sujeito seja mantida, mas a adoção de uma política de inclusão do paciente na vida social. Isso implica não apenas mudanças na estrutura de serviços, mas também no avanço de duas vertentes: a política e a clínica.

Deve ser despertado o interesse político em construir um projeto psicossocial que negue o seqüestro e o isolamento como forma de tratamento, que não distancie o paciente de seu meio social e que favoreça a criação de formas alternativas de atendimento que não produzam rupturas tão definitivas na vida relacional dessas pessoas. Mas também e simultaneamente, a construção de novas formas de se representar a loucura, que permitam o reconhecimento do seu significado social e do valor simbólico da experiência do sujeito, pois a questão da loucura e seu longo, persistente e complexo sistema de segregação sustenta-se em uma significação que se mantém constante nas sociedades modernas. Apoiadas na construção do mito individual e nas fronteiras fortemente estabelecidas entre o público e o privado, a loucura é temida porque ameaça a própria natureza do vínculo social. É uma experiência percebida como refratária à partilha e à reciprocidade, que incide sobre o indivíduo e produz significações individuais incompartilháveis, criando comportamentos ritualísticos individuais e ameaçando negar o social.

Esse sujeito deve ser chamado a ocupar o seu lugar do ponto de vista ocupacional, de sua subjetividade e, sobretudo, do ponto de vista jurídico, como um sujeito com direito à cidadania e a seu exercício. 
Nancy Greca de Oliveira Carneiro \& Luciana de Carvalho Rocha

AMARANTE, P. Psiquiatria Social e Reforma Psiquiátrica. Rio de Janeiro: Editora Fiocruz, 1994 1996. O Homem e a Serpente. Rio de Janeiro: Ed. Fiocruz,

BASAGLIA, F. A Psiquiatria Alternativa: Contra o Pessimismo da Razão, o Otimismo da Prática. São Paulo: Ed. Brasil Debates, 1978.

BOTT, E. Family and Social Network. Londres: Tavistock, 1968

CASTEL, R. AOrdem Psiquiátrica: a ldade de Ouro do Alienismo. 1ำ ed. Rio de Janeiro: Ed. Graal, 1978.

DURKHEIM, E. Sociologia e Filosofia. $2^{\underline{a}}$ ed. Rio de Janeiro: Forense Universitária, 1970.

GOFFMAN, I. Estigma: Notas Sobre a Manipulação da Identidade Deteriorada. 4aㅡ ed. Rio de Janeiro: Ed. Guanabara, 1988.

Manicômios, Prisões e Conventos. São Paulo: Ed. Perspectiva, 1990
- Modelo Médico e a Hospitalização Psiquiátrica: Algumas Notas Sobre as Vicissitudes das Tarefas de Reparação. São Paulo:Ed. Perspectiva, 1990

HOERNER Jr., V. PUCPR-Santa Casa: uma Aliança Providencial. Curitiba: Ed. Universitária Champagnat, 2000.

LAING, R.; COOPER, D. Razão e Violência: uma Década de Pensamento Sartreano. Buenos Aires: Ed. Paidos, 1969.

LOBOSQUE, A. M. Princípios Para uma Clínica Antimanicomial. São Paulo: Ed. Hucitec, 1997.

MIRANDA-SÁ Jr., L. S. Compêndio de Psicopatologia e Semiologia Ppsiquiátrica. Porto Alegre: Artimed Editora, 2001.

PERRUSI, A. Imagens da Loucura: Representação Social da Doença Mental na Psiquiatria. São Paulo: Cortez, 1995.

PESSOTTI, I. O Século dos Manicômios. São Paulo: Ed. 34 S/C Ltda, 1996.
Referências 